\title{
De víctimas, receptadoras y ladronas. La mujer en el mundo del robo y la criminalidad en el Jalisco del siglo XIX ${ }^{1}$
}

\author{
Of the victims, the receptionists and the thieves. The woman in the world \\ of robbery and criminality in jalisco of the nineteenth century \\ SEBASTIÁN PORFIRIO HERRERA GUEVARA \\ Centro Universitario de Ciencias Económico Administrativas (CUCEA) - \\ Universidad de Guadalajara \\ relampagosdeagosto@gmail.com / sebastian.herrera@cucea.udg.mx \\ ORCID http://orcid.org/0000-0001-6029-4483 \\ http://dx.doi.org/10.15304/sm.31.6001
}

\begin{abstract}
RESUMEN
Se propone abordar la implicación de la mujer en el ámbito delictivo en un territorio que padeció una "plaga" de robos, de acuerdo con la opinión pública de la época. En ese contexto de inseguridad y violencia, la mujer fue principalmente víctima de numerosas sustracciones y asaltos, con el agregado que padeció violaciones y vejaciones de tipo sexual. En ese tenor, se trata de una violencia ejercida directamente. En contraposición, y dejando de lado el rol sumiso que culturalmente se le ha asignado, la mujer también fue participe de hechos delictivos, principalmente como receptadora de mercancías y objetos robados y, en última instancia, como ladrona. Lo que la hacía partícipe de consignaciones judiciales, procesos y penas. El trabajo parte de la historia sociocultural del delito, e intenta hacer la reconstrucción de este contexto delictivo desde la perspectiva de género. Se sustenta en fuentes judiciales y prensa de la época.
\end{abstract}

Palabras clave: Delito, Género, Robo, Receptación, Representación.

\begin{abstract}
This article analyzes women's implication in the domain of criminality in an area that, according to contemporary public opinion, was being besieged by a "plague" of robberies. In a setting so heavily marked by public insecurity and violence, women were the victims of innumerable abductions, assaults, sexual attacks and rapes; acts of violence exercised directly on their persons. However, and despite the submissive role so often assigned culturally to women, in some cases they were
\end{abstract}

1 Agradezco a Paulina Jáuregui por el apoyo documental. 
active participants in criminal acts, usually acting as fences of stolen goods and objects, but on occasion also as thieves themselves. Of course, those activities sometimes resulted in arrests, trials and punishment. The analysis follows the approach of the sociocultural history of crime as it seeks to reconstruct this context from a gender perspective. Research was based on judicial sources and newspaper reports from the period.

Keywords: crime, gender, theft, fencing, representation.

\section{INTRODUCCIÓN}

La historia del delito ha tenido un desarrollo sostenido en las últimas décadas en México, recuperando actores sociales que tradicionalmente han sido segregados por otras historiografías. Estos trabajos se han nutrido de los enfoques de la historia social y cultural, específicamente en lo relativo a la reconsideración de procesos históricos tomando en cuenta la participación de grupos como los delincuentes y marginados. Indudablemente este enfoque permite hacer cruces entre las "visiones e imaginarios propios de diversas épocas o fuentes" (Speckman, 2018, p. 11) con la casuística judicial que desmonta el esencialismo normativo, al mostrar que las prácticas y resoluciones institucionales en realidad tienen muchas influencias culturales cómo las percepciones sociales que se tenían en torno a los sexos.

En un sentido más profundo, la historia social ha tenido una enorme influencia en la historia de las mujeres al recuperar sus experiencias y sus procesos de cambio, integración o resistencia. La postura parte de visibilizar a los actores, brindándole sonoridad a los silencios de las fuentes. El paso al enfoque de género abrió la posibilidad de elaborar la reconstrucción de las interacciones entre individuos y la manera cómo se establecen pautas de comportamiento derivadas de estereotipos. Es decir, cómo estas relaciones han estado fuertemente mediadas por percepciones socioculturales (Farge 1991, pp. 87-89, García - Peña, 2016, pp. 3-6). Igualmente, esta perspectiva ha permitido hacer una revalorización metodológica al cuestionar la fuente, buscando nuevas miradas que muestren la participación de los actores sociales que usualmente eran dejados de lado. Al respecto, ante la invisibilidad que históricamente han tenido las mujeres en obras de corte oficialista y positivista que ignoraron su participación en diversos procesos, es importante realizar una crítica documental desde el punto de vista de lo femenino, el tipo de preguntas se deben modificar. Como lo establece Ana Lau Jaiven: "debemos indagar acerca de lo no dicho o no consignado por escrito" (Lau, 1998, p. 165).

La vinculación de la historiografía de las mujeres y la delincuencia permite elaborar este nexo, tan necesario, entre temáticas y fuentes. Los trabajos relativos a la mujer delincuente en el siglo XIX han destacado la participación de ésta cómo un ente activo, si bien marginal, derivado de un deber ser impuesto en procesos políticos, sociales y culturales. Prueba de ello son las reconstrucciones de grupos de mujeres encarceladas que las muestran como personajes activos y transgresores. Así, salen a luz las condiciones de vida que tenían, las diversas profesiones que desempeñaban, los contextos pauperizados, 
las razones y motivos de los crímenes, así como las especificidades y contradicciones de los procesos judiciales (Marín, 2016, pp. 161-163, Avedaño, 2018, pp. 58-60, Sigüenza, 2018, pp. 203-206, Santillán, 2017, pp. 389-418). Otra corriente fuerte es la de los estudios sobre representaciones de la mujer en la esfera pública, en los cuales destacan las convenciones acerca del deber ser y, por ende, los prejuicios vertidos cuando se trata de grupos que rompen los parámetros de la supuesta normalidad, tal es el caso de las llamadas cinturitas o mujeres de la noche o bien el tratamiento que se le daba a los crímenes pasionales (Pulido, 2016, pp. 207-223, Núñez, 2016, pp. 41-44).

Es importante comprender que las descripciones sociales, elaboradas particularmente en la prensa, se hacían por parte de grupos ilustrados y en el poder, con la finalidad de tener argumentos para pensar y reflexionar acerca del rumbo que tomaba el país. La esfera pública decimonónica tenía un evidente carácter deliberativo, se discutía aireadamente el proyecto nacional al tiempo que se reflexionaba sobre las características (deseables e indeseables) de la sociedad mexicana en su conjunto. Para la prensa de finales de ese siglo el honor tuvo un peso específico, tanto en la credibilidad de los periodistas, como en la ponderación de grupos, estratos y divisiones sociales (Piccato, 2015, pp. 35-40). En este caso, las construcciones sobre las mujeres, elaboradas en su mayoría por hombres, abrevaron de mucho de los estereotipos decimonónicos sobre ellas. Así, encontramos plasmadas las ideas de control sobre la sexualidad, el cuerpo y el trabajo. El énfasis en mantener la "buena fama" (caracterizada por la virginidad y la sumisión) y el papel de reproductora. La exaltación de su dolor y sufrimiento como algo propio de su condición. Estas concepciones se forjaron tanto de la herencia colonial como de percepciones de la Iglesia y el Estado por mantener una predominancia patriarcal (Carner, 2006, pp. 101106, Riley, 1988, pp. 44-66).

Generalmente los trabajos se centran en mostrar a la mujer de la élite, la que provenía de la "familia burguesa donde los roles masculino y femenino se solidifican y estereotipan" pues "es en la conducta de la mujer en donde se cifra el buen nombre de la familia, signo de estatus y jerarquía" (Ramos, 2006, p. 152). En contraposición, el abordaje de las mujeres inmiscuidas en la trasgresión de la norma provenía, innegablemente, de los prejuicios sociales, económicos y de género que permearon en las discusiones públicas de la época. Al criminal se le trataba duramente en las reflexiones periodísticas, con desprecio y sorna. Se exigían continuamente las penas más severas. Así, para la mujer delincuente, la escandalosa, la violenta, había un doble estigma

En ese sentido, el ámbito del robo, es un contexto que ha sido primordialmente trabajado como un escenario masculino, se habla de ladrones, de sus idearios, de su mística y, bajo esta perspectiva, la mujer es sólo un agregado en la historia, un pivote que permite reconstruir la crueldad del individuo o bien su galantería (la literatura bandolera suele posicionarse en los extremos). La idea de este trabajo es recuperar la propuesta historiográfica de la historia sociocultural de delito para elaborar una reconstrucción del ámbito de robo y la criminalidad en el Jalisco decimonónico retomando la participación que tuvieron las mujeres. 


\section{LA MUJER EN EL ÁMBITO DEL ROBO}

El estado de Jalisco durante el siglo XIX experimentó diversos procesos que transformaron su composición política y social. Durante esa centuria se luchó intensamente por consolidar un proyecto político que le diera rumbo tanto al país como a la región; se buscó la modernización a través de un incipiente proceso de industrialización que introdujo tecnología en ciertas áreas de las comunicaciones y en algunas haciendas; se intentó transformar al indígena en ciudadano, dejando de lado las propiedades comunales y promoviendo la individualización; se procuró una educación laica y tendiente al impulso de la técnica. En estos procesos de profunda transformación hubo numerosas crisis políticas, enfrentamientos armados y rebeliones de corte agrario que caracterizaron un periodo de inestabilidad que Luis González y González denominó como "el siglo de las luchas" (González, 2002, pp. 3 - 4).

En ese contexto convulso la criminalidad se extendió a niveles alarmantes, especialmente los robos y asaltos que sucedían principalmente en ámbitos rurales: caminos, veredas, ventas y pueblos, así también en las inmediaciones y en los arrabales de las ciudades importantes como Guadalajara (capital del estado) o Lagos (donde se llevaba a cabo una de las ferias comerciales más importantes del país). Estos delitos en sus diferentes variantes fueron bastante comunes en el Jalisco decimonónico, prueba de ello son las numerosas y sistemáticas referencias a bandidos, ladrones y delincuentes que se pueden encontrar en la prensa, los diarios de viajeros o las memorias de gobierno. Estas publicaciones intentaban darle sentido a una criminalidad que se estaba desbordando de los cauces impuestos por una exigua maquinaria de control social. Se hablaba de una "plaga" que se debía combatir en beneficio del cuerpo social; de este modo, se evidenciaba el descontrol que tenía la autoridad al tiempo que se exigía la implementación de castigos más severos. Un periódico local, El Mundo, llegó a afirmar lo siguiente: “¿qué pasa en Jalisco? ¿Estamos ya á merced de los bandoleros? ¿Cuál es la protección que el comercio de esa ciudad y de los pueblos recibe de los poderes públicos del Estado, bajo estos aspectos? ¿Estamos ya reducidos a nuestros privados esfuerzos?". ${ }^{2}$ Un año después, de forma lapidaria $E l$ Republicano Jalisciense daría, a su manera, respuesta a estas interrogantes al asegurar: "enfermedades estraordinarias, demandan esfuerzos estraordinarios [sic.]. Delitos horribles, penas severas". ${ }^{3}$ La pena draconiana era la solución que se proponía desde la esfera pública, la transgresión penal se sortearía con castigos severos y aleccionadores, así como encierros prolongados.

Este tipo de notas fueron una constante en la esfera pública. Algunas décadas después, Juan Panadero (uno de los periódicos más longevos y constantes de las últimas décadas del siglo) afirmaba lo siguiente sobre los robos: "siguen a rienda suelta en esta

2 BPEJ, HH, El Mundo, Guadalajara, martes 5 de octubre de 1847, vol. 1, núm. 9 (alcance), p. 2.

3 BPEJ, HH, El Republicano Jalisciense, Guadalajara, martes 15 de agosto de 1848, vol. 3, núm. 7, p. 4. 
pobre ciudad y en los caminos". ${ }^{4}$ Ocho años después reflexionaba: "los ladrones han hecho ya muchas víctimas, no solo de su rapacidad, sino también de lo sanguinario y cruel de sus instintos". ${ }^{5}$ El órgano se quejaba de la falta de vigilancia y preparación por parte del cuerpo de policía; en ese sentido, era necesario reformar y sanear las instituciones. El gobierno no podía negarse a procurar y garantizar la seguridad de sus habitantes.

Desde una perspectiva más amplia, el matiz sobre los discursos acerca de la criminalidad estribó en que, hacia las décadas postreras de la centuria, la población urbana comenzó a ganar visibilidad en detrimento del escenario rural. La ciudad y sus arrabales fueron los espacios preponderantes en las publicaciones acerca de los crímenes. Adicionalmente, se comenzaron a publicar notas que destacaban la violencia y saña de los ladrones y, en general, de los delincuentes. En ese cúmulo de notas periodísticas, la mujer apareció predominantemente cómo la víctima pasiva y débil o bien como una trasgresora social que no se adecuaba a las pautas sociales impuestas.

Lo anterior debido a que el ámbito del robo, desde el punto de vista de los perpetradores, era mayoritariamente masculino. El ladrón común era el hombre de estrato bajo, generalmente ligado al campo y con una inseguridad laboral latente que lo orillaba a delinquir para obtener un ingreso extra a su profesión principal. Pocos eran los que se dedicaban de tiempo completo. Diferentes autores al momento de realizar la descripción de estos personajes siempre se refieren a hombres, por ejemplo, Paul Vanderwood habla de los bandidos como los desertores, los muchachos aburridos, oportunistas, aventureros y fugados de la prisión (Vanderwood, 1986, p. 30). Por su parte, Ignacio Manuel Altamirano en su novela El Zarco, publicada en 1901, realizó la siguiente descripción del líder del grupo de salteadores: "él era joven, no tenía mala figura: su color blanco impuro, sus ojos de ese color azul que el vulgo llama zarco, sus cabellos de un rubio pálido y su cuerpo esbelto y vigoroso, le daban una apariencia ventajosa pero su ceño adusto, su lenguaje agresivo y brutal, su risa aguda y forzada" (Altamirano, 2010, pp. 32 - 33). En este caso, estos hombres podían ser incluso carismáticos, con ciertas cualidades de líderes, pero al mismo tiempo prosaicos y violentos.

Un estudio sobre el bandidaje en Jalisco muestra que en un $97.55 \%$ los hombres fueron los acusados de robar y solamente en un minoritario $2.45 \%$ se imputó a mujeres. Este último porcentaje lo constituyen 8 casos, en 6 de los cuales se denunció a las femeninas por receptación; es decir, ser cómplices de un ladrón. El par de casos restantes fueron de robo menor, en el primero María Bonifacia Cruz (20 años, soltera) participó junto con otros dos individuos en una ratería ocurrida en Teocaltiche. La segunda ladrona fue María Ignacia García (40 años, viuda) quién en solitario robó dos rebozos a Juan Ramírez en su casa, no lo hizo violentamente, sino que esperó hasta que éste salió a trabajar. No hubo sentencias mayores en ambos expedientes (Herrera, 2017, pp. 229 - 230).

4 BPEJ, HH Juan Panadero, Guadalajara, jueves 5 de diciembre de 1872, tomo II, núm. 35, p. 6.

5 BPEJ, HH, Juan Panadero, Guadalajara, jueves 30 de septiembre de 1880, tomo IX, núm. 848, p. 2. 
Ante esto cabe preguntarse, ¿cuál fue la participación y la experiencia de la mujer como sujeto social dentro de este contexto de una criminalidad elevada? Una primera respuesta estriba en las convenciones de género que se tenían para la época. El ser gavillero, independientemente de todas las atribuciones prosaicas y moralmente reprobables, era el sucedáneo de alguien arrojado, valiente, masculino. En tanto, la participación de la mujer, en ese contexto, se limitaba a ser la víctima, la pasiva. Estos roles están claramente definidos, por ejemplo, en la mencionada novela El Zarco dónde los hombres son los que luchan y roban, los que planean y deliberan, son los que salen a proteger a las damas secuestradas, son los que imparten justicia; en cambio, las mujeres son las robadas, de las que se espera un tipo de comportamiento específico, son las que enloquecen porque sus nervios no daban para más (Altamirano, 2010).

Ahora bien, en términos prácticos, dedicarse al bandidaje conllevaba sus riesgos, existía la posibilidad de perder la vida en cada asalto, ya sea por un encuentro con cuerpos de seguridad o bien porque las propias víctimas, en un arrojo de valentía, se defendían y enfrentaban a sus ladrones (es importante recordar que para la época era común que los viajeros lo hicieran en grupo, armados y, si era económicamente posible, con seguridad contratada). En ese sentido, los expedientes judiciales muestran que el bandido más joven era el que estaba vinculado con los asaltos más violentos que requerían de mayores habilidades físicas; en cambio, a los viejos y a las mujeres se les relacionaba más con las raterías, esos robos menores, nimios, que eran producto más de una astucia u oportunidad, que debido a un enfrentamiento violento y arriesgado (Herrera, 2017, pp. 227 - 229). Elisa Speckman coincide en lo esencial al establecer que las mujeres "practicaban el hurto casual en almacenes o robos menores en su trabajo y lugar de habitación, los varones, con frecuencia empleaban la fuerza" (Speckman, 1997, p. 188). De este modo, encontraremos a la mujer ladrona en las llamadas raterías, alejadas del enfrentamiento físico pero centradas en la observación, en el aprovechamiento de la oportunidad.

Juan Panadero, por ejemplo, hablaba de las "bolseadoras" que trabajaban en la zona céntrica de Guadalajara hurgando las bolsas, se valían de la congestión de los sitios urbanos para llevar a cabo sus acciones: "en donde quiera que hay bola meten cinco y sacan seis, y cuando no pueden hacerlo fácilmente, se ayudan de unas tijeras de que andan bien provistas". ${ }^{6}$ En estos pequeños robos se buscaba sacar ventaja de la distracción del transeúnte, del fervor y concentración de la festividad cívica o religiosa, de la plática originada a propósito. La idea era tomar las billeteras o cualquier otro objeto de valor. La ratería era un tipo de delito de bajo impacto, común, pero pocas veces denunciado debido a que se tomaba cómo algo de poca importancia, incluso cotidiano. Usualmente, se resolvía en la justicia ordinaria. Ello explica por qué representaba una proporción muy pequeña de casos dentro del amplio número de expedientes relacionados con la delincuencia en los tribunales superiores.

6 BPEJ, HH, Juan Panadero, Guadalajara, domingo 16 de marzo de 1873, tomo II, núm. 64, p. 4. 
En el mismo tenor, hubo un robo en una vinatería de la ciudad, en una zona céntrica donde ya se habían realizado numerosas sustracciones, solamente que en este caso el policía vio salir a los ladrones vestidos de mujeres. Juan Pandero fiel a su estilo afirmó que el cuico siguiendo su naturaleza les espetó algunos piropos. ${ }^{7}$ Evidentemente, el hecho de disfrazarse tenía la función para los ladrones de pasar desapercibidos, de ser tomados por otras personas. En este sentido, hay una vinculación con el ladrón prototípico de caminos, el que robaba a placer en las décadas intermedias del siglo XIX, quién usualmente llevaba un paño para cubrir su rostro. En ambos casos, el anonimato era fundamental si se quería continuar en la carrera delictiva. Sin embargo, el hecho que hayan sido caracterizados como mujeres podría ser un simbolismo de un robo de "características femeninas"; es decir, un robo menor que bien podía pasar desapercibido como otras de las acciones que realizaban aquellos individuos considerados "irracionales", incluso se les podía tener algo de condescendencia. Tal vez por ello, el periódico tituló de forma despectiva a la nota como: "robito".

En el siglo XIX la mujer tenía un rol colateral como actor social, pues en la mayoría de los casos era dependiente económicamente y carente de derechos políticos. Sintomático de esa afirmación resulta, por ejemplo, la ausencia de profesiones de mujeres registradas en los expedientes, en los cuales era común asentar nombres, edades, estado civil y profesiones de víctimas, acusados y testigos. En el caso de individuos del sexo femenino solamente se escribían los dos primeros campos, de lo cual se puede inferir, en un primer momento, que su participación se circunscribía a la administración del hogar. La cocina, la casa, la iglesia, se pensaban como su lugar natural; de hecho, en numerosos casos ahí aparecen, en espacios desde donde observaban y se vinculaban con los hechos delictivos, de los cuales participaban marginalmente.

En los textos publicados en la esfera pública de la época se hablaba de los diversos roles y participaciones que deberían tener los actores sociales de acuerdo a su sexo y condición social. Este tipo de representaciones se alimentaban de estereotipos forjados por la burguesía principalmente para establecer pautas de comportamiento vinculadas a los sexos. De acuerdo con Carmen Ramos se trata de una "burguesía de aparición lenta y tardía, de origen terrateniente o burocrático más que industrial", la cual a través de sus medios de enunciación trasmitió una serie de estereotipos que reforzaron tanto las nociones patriarcales como las señoriales (Ramos, 2006, p. 152). Así, desde los tratados naturalistas del siglo XVIII hasta el positivismo decimonónico se buscó dotar de un sustento sólido y racional a toda una serie de argumentos que justificaban y reforzaban la noción de inferioridad de la mujer como un ser frágil, débil, nervioso, histérico, enfermo y limitado (Isais, 2014, pp. 233-234).

De este modo, en la esfera pública y a través de numerosos debates se fueron forjando los tipos ideales que constituirían los integrantes de la sociedad moderna mexicana. 
Por supuesto, el ciudadano era el avante defensor de las leyes, el bandolero era la encarnación de los males y los vicios de la sociedad. A la mujer se le relacionaba, por ejemplo, con la gestión de la esfera doméstica (para lo cual se le daban una serie de consejos), su labor estaba con la familia y se le vinculaba a valores como la obediencia, el recato y el pudor. Además, se le permitía publicar poemas y narraciones literarias, propias de su condición (Hernández, 2015, pp. 160-161). En Jalisco se replicaron en términos generales estas ideas; de este modo, según la esfera pública regional las cualidades principales de la mujer eran: "la modestia, la belleza moral y la honradez. Estas debían ser ordenadas y laboriosas, pero sobre todo honradas" (Benítez, 2014, p. 111).

Al respecto, en una carta de las mujeres de alcurnia de México dirigida a Porfirio Díaz, lo que Ramos Escandón denominó "las señoritas porfirianas" (Ramos, 2006, p. 152), en la cual solicitaban la liberación de ciertos estudiantes presos, se puede leer lo siguiente sobre el llamado bello sexo: "la misión de la mujer es de paz y en su corazón debe germinar el amor a la patria, como la más santa de las virtudes: tanto las costumbres como la naturaleza le señalan un papel pasivo delante de los acontecimientos que deciden del porvenir de la nación". Aquí, la argumentación iba relacionada con la poca seriedad con la que se tomaba a la mujer en el ámbito político nacional; salvo excepciones, se consideraba que ésta no debía tomar partido en las discusiones políticas nacionales, para ello se le reservaban las publicaciones consideradas literarias. Aun así, este grupo de mujeres se atrevían: "hemos levantado nuestra débil voz y otra vez más decimos que esperamos no ser desoídas". Después afirmaban: "las mujeres somos el símbolo de la paz en las tormentosas luchas de la existencia; en nuestra debilidad reside nuestra fuerza". ${ }^{8}$ Por supuesto, el presidente desestimó la solicitud confirmando los temores fundados de dicho sector social por ser ignoradas.

Ahora bien, estudiar la criminalización de las mujeres en términos históricos puede igualmente mostrar la compleja y diversa experiencia que tuvieron en un contexto donde supuestamente su accionar debería estar regulado por las construcciones morales en turno. En ese sentido, hay estudios de caso tanto internacionales como nacionales que muestran a las mujeres trabajadoras, generalmente de clases bajas, vinculadas a diversas profesiones más allá de comandar un hogar (Avedaño, 2018, pp. 54-59, Speckman, 1997, pp. 185-190). Los trabajos que desempeñaban deberían ser considerados “decentes" en el marco de una sociedad que ponderaba la civilidad, la cortesía y los modales como cualidades de todo ciudadano, pero especialmente de ellas; aun así, se limitaban sus labores por las atribuciones vinculadas a su sexo, circunscribiendo su área de acción a las llamadas ocupaciones femeninas. Para el caso jalisciense, un estudio sobre mujeres "robadas" o raptadas reveló, en su muestreo documental, que la mayoría estaban vinculadas a labores domésticas como: costureras, lavanderas, planchadoras, sirvientas, parteras, curanderas, telegrafistas, entre otras (Benítez, 2014, p. 115). Por supuesto, no se trataba

8 BPEJ, HH, Juan Panadero, Guadalajara, domingo 16 de agosto de 1885, tomo XIV, núm. 1365, p. 1. 
de una liberación femenina (pese a que ciertos editorialistas escandalizados de la época se manifestaron azorados por tener que otorgar igualdad de derechos), sino de la inclusión de la mujer en el ámbito de una dinámica de beneficio económico derivada de la necesidad de los industriales por incorporar mano de obra barata. Al respecto Arlette Farge establece: "tanto en las sociedades precapitalistas como en las sociedades industriales, la dominación masculina es indisociable del modo de producción de los bienes que excluye a las mujeres de los beneficios de su trabajo" (Farge, 1991, p. 90).

De esta manera, la misma oligarquía rompió con un modelo pregonado como benéfico socialmente, pues la idea de la mujer como administradora del hogar y como divulgadora de una educación adecuada a los valores morales dominantes, establecería las bases del orden y estabilidad. Asignar roles, tanto en la familia como en la sociedad, era un elemento central en el proceso de construcción de un Estado moderno, pues ello señalaría el norte y brindaría el derrotero a un pueblo que experimentaba numeras convulsiones sociales. Estas mujeres, por lo tanto, representan la disidencia de su rol asignado, la ruptura de un molde de "normalidad" que se fraguó sobre ciertos constructos que buscaban perpetuar un modelo social desigual. Para Speckman se trata de trasgresoras sociales que no se adecuaban a los estereotipos impuestos por una burguesía que no comprendía que muchas mujeres trabajaban por necesidad, vivían hacinadas en vecindades o se amancebaban con algún masculino. Por lo tanto, es importante entender que "la criminalidad no era un fenómeno propio de 'señoritas porfirianas' o de las 'señoras decentes', es decir, de las mujeres que respondían al modelo" (Speckman, 1997, p. 193). En ese sentido, los estudios que vinculan a la mujer con la delincuencia (especialmente aquellos que han sido influenciados por la historia social) muestran que las prácticas no siempre se adhieren a las normatividades, ni a los discursos. Al contrario, evidencían ese transcurso dinámico de la historia en el cual están imbricadas las relaciones sociales.

\section{LA DULCE CARGA, DE VÍCTIMAS A BOTINES}

Una de las características de la sociedad decimonónica fue la constante y sistemática violencia que se manifestaba de forma cotidiana. Por ejemplo, William Taylor (1993, pp. 63-103), a través de un análisis sistemático de expedientes judiciales sobre asesinatos en Jalisco, muestra un contexto en el cual una frase, palabra u gesto podrían interpretarse como una afrenta al honor, a la virilidad, lo cual desencadenaba un ataque, un duelo o un combate hasta la muerte. Por supuesto, en ese contexto la mujer fue protagonista principal en numerosos casos de robos, asesinatos y riñas.

En primer lugar, estaban las expresiones que se utilizaban en la esfera pública para referirse a este grupo social. Había desde las consideradas "halagadoras" como el bello sexo o la luz del hogar (que en realidad reforzaban los roles de género), hasta las que eran descripciones de la anormalidad o la otredad, adjetivos para referirse a aquellas mujeres involucradas en actos delictivos como: "infelices" o "escandalosas". Para señalar a un 
grupo de prostitutas Juan Pandero las describió como: "un par de viejas alegres". ${ }^{9}$ Las descripciones de estas mujeres también destacaban ciertas características como el desenfreno, aspecto opuesto al recato que el rol social fomentaba. Así, se hablaba de un grupo "de alegres costumbres" que eran "una corona de espinas" para los vecinos tranquilos y decentes de los diferentes barrios tapatíos. ${ }^{10}$ Otra nota similar hablaba de un grupo de mujeres que se la pasaban viviendo en "perpetua chorcha" para referirse a las numerosas fiestas y ruidos que generaban en el barrio de Mexicaltzingo, un sitio de origen popular: "no hay noche en que no disfruten de las alegrías del vino y el canto: la guitarrita es para ellas un mueble indispensable [...] arrojan por aquellas bocas unos berridos capaces de reventar el tímpano de las orejas de un sordo". ${ }^{11}$

La predominancia de las ideas de decencia y pudor hacía que fácilmente se interpretaran ciertas acciones en las relaciones entre individuos de diferentes sexos como sucedáneos de las "malas costumbres", ello sucedía en las interacciones laborales donde, en términos ideales, se cuidaban las compañías y se moderaban los dichos. En ese contexto era muy fácil llamar prostituta a una mujer, por ejemplo, en la prensa fueron constantes las denuncias contra las operarias cigarreras por "sus supuestas costumbres licenciosas", aunque en realidad no hubiera sustento sólido para dichas afirmaciones, durante todo el siglo XIX (Saloma, 2000, p. 9).

El paso de ese tipo de representaciones a la violencia física fue algo ampliamente registrado en las fuentes históricas. Por ejemplo, en un estudio sobre la violencia en el Estado de México durante el Porfiriato la mujer aparece predominantemente como la víctima (González y Iracheta, 2006, p. 120). Para el caso jalisciense, haciendo un recorrido de los textos publicados por Juan Panadero se encuentra un gran número de notas señalando actos violentos en los cuales la mujer aparecía cómo la víctima. En algunos casos, solamente se hablaba de golpes o moretones como le ocurrió a la señora Simona Michel una mañana en que su mozo la quiso asaltar, ella opuso resistencia ante el ataque intempestivo, prodigando gritos que despertaron a los vecinos y oponiendo, en la medida de sus posibilidades, resistencia suficiente para disuadir al perpetrador. ${ }^{12}$ En este caso el órgano destacaba la suerte que había tenido la referida mujer al salvarse de un robo en un contexto en el cual era algo que sufrían cotidianamente los ciudadanos.

En otros casos, las agresiones físicas escalaban de nivel hasta llegar al homicidio, por ejemplo, cuando "un infame hombre asesinó á una mujer en la plaza de Venegas [en el centro de la ciudad] dándole una puñalada en el corazón” o bien cuando Rosa Martínez fue herida en la espalda por un puñal que le encajó un "pelado". ${ }^{13}$ En estos textos, aparte

9 BPEJ, HH, Juan Panadero, Guadalajara, domingo 19 de mayo de 1889, tomo XV, núm. 2028, p. 2.

10 BPEJ, HH, Juan Panadero, Guadalajara, domingo 19 de mayo de 1889, tomo XV, núm. 2028, p. 2 y BPEJ, HH, Juan Panadero, Guadalajara, jueves 15 de junio de 1882, tomo XI, núm. 1027, p. 2.

11 BPEJ, HH, Juan Panadero, Guadalajara, jueves 20 de mayo de 1889, tomo XV, núm. 2030, p. 2.

12 BPEJ, HH, Juan Panadero, Guadalajara, jueves 23 de octubre de 1890, tomo XV, núm. 2212, p. 3.

13 BPEJ, HH, Juan Panadero, Guadalajara, jueves 2 de junio de 1887, tomo XV, núm. 1541, p. 2 y BPEJ, HH, Juan Panadero, Guadalajara, jueves 24 de octubre de 1889, tomo XV, núm. 2101, p. 3. 
de registrar los hechos acaecidos en los sitios más peligrosos de la ciudad, se reforzaba la invisibilidad de la mujer porque no se daban nombres (por lo menos en el primer caso) y al no reflexionar o profundizar sobre las razones que motivaron los hechos, estos acontecimientos permanecían en el ámbito de lo superficial, se tomaban como simples referidos.

Es posible establecer que este tipo de notas también respondieron a un creciente interés por mantener una cobertura de corte sensacionalista en la prensa. Si bien, la llamada nota roja tuvo su esplendor en décadas posteriores, resulta perceptible un cambio en la forma que se abordaron estos temas. Hay un tránsito de un periodismo que privilegiaba el intercambio de opiniones y la reflexión, a otro que prodigaba textos más informativos como el titulado: "crimen de sensación” dónde se remitía una noticia del órgano $E l$ Nacional que señalaba la historia de un individuo de la clase adinerada de México que sepultó viva a su mujer en una casa de un barrio apartado de la capital. Igualmente estaba la cobertura de una mujer muerta que tenía un tajo en la garganta y que fue encontrada en un cuarto vacío, suceso por demás misterioso ya que la susodicha no fue despojada de su ropa y dinero, lo que hubiera justificado el móvil del robo. ${ }^{14}$

Otro matiz era la relación que tenía la mujer con las figuras de autoridad inmiscuidas en los hechos delictivos. Aquí, la impunidad ante la violencia fue un elemento que se encontraba presente, como fue el caso de una femenina que recibió una cortada en la cara de parte del vicepresidente del municipio de Tequila. El juez liberó al imputado pese a la petición de varios miembros de la comunidad por un castigo ${ }^{15}$ La policía en la ciudad de Guadalajara fue objeto de numerosas críticas que evidenciaban su poca preparación y negligencia. En este sentido, es posible encontrar una narración acerca de una mujer que corría por los jardines de la Escobedo [la penitenciaría del estado] huyendo de su marido, "la pobre mujer iba que se caía de muerta de susto" pidiendo auxilio. En lugar de obtener ayuda, fue reprendida por la policía local, por escandalosa. Los también llamados cuicos, en particular el inspector del $6^{\circ}$ cuartel, le pidieron que los acompañara a la comisaría. Ante la negativa, el mencionado inspector "se sulfuró y sin considerar que se trataba de una débil mujer" pidió a sus subalternos que la llevara a rastras, de otro modo no eran lo suficientemente hombres. ${ }^{16}$ Aquí resulta interesante cómo los roles de género están presentes, la masculinidad no permitía ceder ante una mujer y no toleraba que su contraparte no acatara sus órdenes. Para demostrar la hombría habría que manifestar la autoridad aunque sea violentamente.

Las mujeres no solamente fueron las víctimas de la violencia, sino que también se constituyeron como botines. El rapto fue uno de los delitos más comunes y visibilizados en las últimas décadas del siglo XIX jalisciense. Este accionar reforzaba la idea de la mu-

14 BPEJ, HH, Juan Panadero, Guadalajara, domingo 20 de noviembre de 1887, tomo XV, núm. 1591, p. 2 y BPEJ, HH, Juan Panadero, Guadalajara, domingo 23 de enero de 1881, tomo X, núm. 881, p. 3.

15 BPEJ, HH, Juan Panadero, Guadalajara, domingo 16 de noviembre de 1890, tomo XV, núm. 2274, p. 2.

16 BPEJ, HH, Juan Panadero, Guadalajara, domingo 28 de noviembre de 1880, tomo X, núm. 865, p. 2. 
jer como objeto y evidenciaba la idea de propiedad (del hombre y la familia) sobre ella. Lo importante era mantener, en la medida de lo posible, el honor de la parte despojada. Como menciona Françoise Carner "el rapto, que destruía la honra sexual de la muchacha, obligaba a los padres a aceptar como marido de su hija a un hombre que antes no hubieran aprobado" (Carner, 2006, p. 102). Conforme pasó el siglo este tipo de hechos fueron tomando un cariz de mediación privado, aunque también se condicionaban las uniones y si estás eran demasiado desfavorables se prefería la deshonra. De este modo, esposos, familia y Estado entraban en los arreglos; al respecto Laura Benítez establece: "había que cuidar a las mujeres ya que ante la ley eran consideradas como menores, es decir, indefensas y desprotegidas en comparación con los hombres, por lo tanto, debía defendérseles" (Benítez, 2014, p. 302). Por ejemplo, la gavilla del bandido Mauricio Alvarado, en el poblado de Cuquío (al interior del estado), se robó: "una provisión de muchachas que les hicieran menos amargas las peripecias de la vida de bandidos", los ladrones al poco de andar abandonaron "la dulce carga". ${ }^{17}$ Esta expresión resulta sintomática: un cuerpo del cual era posible obtener disfrute, una propiedad intercambiable de la que se podía lograr utilidad y, como todo objeto valioso, proclive a ser sustraído.

En los casos de mujeres robadas, era muy importante lo que sucedía después del rapto pues si ésta se enamoraba del ladrón, como sucedía en El Zarco, inmediatamente perdía el apoyo de la familia, porque se consideraba indecente (aunque en dicha historia el arrepentimiento era central para volver al cauce moral imperante). Cuando una niña de 13 años de edad fue privada de su libertad por un grupo de "mujeres alegres", según la nota, pasó la noche en el burdel y al día siguiente fue registrada en el padrón de "las perdidas" como se denominaba al registro de prostitutas que podían ejercer en la ciudad durante los años finales del siglo XIX. ${ }^{18}$ Es decir, en esta ocasión el robo de la mujer también conllevó su iniciación en el oficio sexual.

La invisibilidad era la característica principal. En los expedientes judiciales era común hacer un recuento de objetos sustraídos, se tomaban las declaraciones de hombres y mujeres que habían experimentado el robo ya sea de forma violenta o no. Estadísticamente se nombraba a los hombres como los afectados, en un porcentaje de $87.45 \%$ en comparación de $10.98 \%$ según un estudio sobre robos en Jalisco (Herrera, 2017, p. 239). Por supuesto, estas cifras responden a los roles sociales, en los cuales la mujer no contaba como actor por sí misma, sino que se le relacionaba con el hombre o el padre de familia. Sin duda, esta es una de las más grandes omisiones que se puede encontrar en las fuentes históricas, a las cuales hay que cuestionar buscando reconstruir la participación femenina en estos procesos.

Un caso ejemplar de esta invisibilidad reside en el asalto domiciliado, un tipo de sustracción especialmente agresivo pues al encierro del hogar se desataban toda una serie

17 BPEJ, HH, Juan Panadero, Guadalajara, jueves 25 de septiembre de 1879, tomo IX, núm. 743, p. 3

18 BPEJ, HH, Juan Panadero, Guadalajara, jueves 7 de julio de 1887, tomo XV, núm. 1550, p. 2. 
de pulsiones violentas y enfrentamientos que se agregaban a los objetos de valor tomados. Cuando la gavilla de Irineo de Jesús Juárez (casado, 26 años, labrador), compuesta por alrededor de seis hombres, entró a la casa de José Castillo, los hombres amarraron al mencionado y le pidieron a su esposa Inés Cortes que les hiciera de comer, para ello mataron las gallinas que había en el corral. Después los ladrones violaron a Cortés en numerosas ocasiones enfrente de su marido. El asalto se extendió alrededor de cinco horas, durante las cuales los asaltantes estuvieron con la cara cubierta con paños todo el tiempo. Al acusado, el mencionado Juárez, lo encontraron en posesión de una silla de montar y una espada que eran propiedad del dueño de la casa, ello fue lo que lo delató. En esta ocasión, la primera instancia de Tepic afirmó que ante el hecho agravante del forzamiento, los malhechores lo hicieron no por necesidad, sino por: "puro deseo de martirizar abusaban de la fuerza recreándose en el dolor que sufriría José Castillo". ${ }^{19}$

De lo anterior destaca en primer lugar la saña con la cual realizaron el robo, especialmente por la violación de Cortés. Es posible que la intención primaria no fuera cometer un asalto como tal, el modus no concuerda con otros ejemplos, especialmente por las varias horas que permanecieron en la casa. Es plausible también que los hombres tuvieran una reyerta personal contra Castillo y buscaron venganza de la peor forma posible. Particularmente notoria fue la declaración del juez de primera instancia tepiqueño, quién se lamentó por el daño y el dolor que le hicieron al esposo, no a su mujer, que basado en lo anterior pasaba a un término secundario. Como era usual en estos casos el expediente llegó al Supremo Tribunal de Justicia donde el abogado defensor solicitó el indulto (se le había impuesto la pena de muerte), lo que en dicho contexto generalmente se brindaba intercambiando el fusilamiento por 10 años de encierro. Aquí destaca que la petición fue rechazada afirmando que este tipo de delitos no podían quedar impunes debido a la extrema violencia del caso. Al respecto el fiscal del estado mencionaba: "sólo la pena capital puede retraer a los vandidos [sic.] de cometer sus crímenes por el terror que ella inspira". ${ }^{20}$ La idea de fondo era el castigo aleccionador, pero es sintomático que se buscara reparar el daño simbólico perpetrado, el fusilamiento como elemento que restauraría el honor mancillado de un esposo.

\section{RECEPTACIÓN, UNA CONTRIBUCIÓN INVISIBLE}

Dentro de las fuentes judiciales el segundo papel que desarrollaron activamente las mujeres fue el de receptadoras; es decir, cómplices de los ladrones. Esta actividad no era secundaria en absoluto; al contrario, era fundamental para la concreción exitosa de la sustracción. La receptación, en un primer nivel, consistía en guardar de manera eficiente los botines, además que las mujeres en muchas ocasiones corroboraban las coartadas que

19 BPEJ, STJ, Criminal,1857, caja 4, exp. 16345.

20 BPEJ, STJ, Criminal,1857, caja 4, exp. 16345. 
los acusados establecían, haciendo más difícil demostrar la culpabilidad. Ellas declaraban que alguien (un desconocido) les había dado a guardar lo robado, ellas confirmaban que habían pasado la noche con el acusado en su casa. En un nivel más profundo esta actividad se relacionaba con la colocación y reventa de objetos. En ese sentido, el robo domiciliado que cometieron José Sánchez y Dimas Flores ejemplifica el papel de la mujer como receptadora. Ambos ladrones robaron una tienda en Lagos por la noche, entraron y salieron con dinero y vino. Al momento de repartir el botín, Flores, quién iba acompañado por una mujer de la cual no se mencionan más detalles, pero de quien se infiere tuvo una participación como cómplice y receptadora, argumentó que ellos deberían obtener una porción mayor que la de Sánchez, ante lo cual aseguraba: "las mujeres de los ladrones entraban también en parte". ${ }^{21}$ Después de hacer la repartición, como solía suceder en los casos prototípicos de robo, se terminaba la alianza delictiva y cada quien partía por su lado.

Esta participación como colaboradora también es posible encontrarla en casos de abigeato, un tipo de robo con una alta incidencia estadística que se especializaba en la sustracción de animales como vacas o caballos. Este tipo de delito sucedía generalmente al paso, aprovechando la oportunidad de tomar piezas que estaban pastando libremente o sustrayéndolas subrepticiamente de los corrales. La declaración de Felipe Núñez (gañan, 22 años, casado) evidencía el modo de operación prototípico de los abigeos, pues en su confesión aseguró: "anoche salí de mi casa con intención ya de robarme una res y fui al rancho de Don Faustino Santos y en un barbecho de la casa andaban dos bueyes y de ellos me traje una y la maté en mi casa".22

El elemento principal para el éxito de este tipo de sustracciones era el movimiento. Era necesario colocar, revender o esconder lo robado. En el caso de los animales estos aparecían en otras poblaciones, en carnicerías o simplemente se encontraba su carne ya destajada en las casas de los acusados o sus familiares. Para contrarrestar estas prácticas se marcaba el ganado, pero en Jalisco no hubo un padrón de identificación de marcas efectivo sino hasta finales del siglo XIX (como sí pasó en territorios donde había hatos de animales de gran tamaño y valor económico como, por ejemplo, en Chihuahua). Lo que si existió fue una red de complicidades en las ventas. Este tema ha sido abordado por otros historiadores para otros escenarios (De Souza,2001, pp. 525-528, Rafart, 2008, pp. 110-115), los cuales demuestran la imposibilidad de un buen funcionamiento del mercado negro de mercancías robadas sin la colaboración de vendedores, receptadores y consumidores. En ese sentido, era necesaria la existencia de una red de ilegalidades que explicaría cómo, en un par de días, una pieza podía aparecer en poblaciones lejanas sorteando garitas sin papeles de identificación o bien que la carne se colocaba rápidamente en carnicerías de Guadalajara donde se vendía a precios más competitivos. Estas acciones

21 BPEJ, STJ, Criminal, 1850, caja 4, exp. 10910.

22 BPEJ, STJ, Criminal, 1851, caja 2, exp. 11403, f. 3. 
serían laboriosas, peligrosas e ineficientes si se hubieran realizado de manera individual. Sin duda, muchas mujeres familiares, parejas y compañeras estuvieron inmiscuidas en estos procesos.

La receptación era una de aquellas acciones elusivas que no se podían determinar con certeza. Como era considerado un delito menor en comparación con el robo (el abigeato no estaba tipificado en la legislación jalisciense), muchos ladrones, incluso líderes de gavillas, optaban por coartadas que les permitían, en el peor de los casos, mostrarse como los auxiliares de ladrones desconocidos que les habían pedido pasar ganado por garitas o llevar animales robados a cambio de alguna cantidad. De este modo, obtenían una sentencia reducida que les brindaba la posibilidad regresar a la libertad en un periodo razonable. En ese tenor, la mujer acusada de receptación aparecía en los expedientes como un eslabón secundario de una cadena que buscaba a los ladrones principales. De alguna manera, la colaboración en la participación delictiva replicaba, a nivel micro, los roles sociales que les estaban destinados tanto a los hombres como a las mujeres, los primeros llevando las tareas pesadas, peligrosas, físicamente demandantes, las segundas llevaban las labores más suaves (Isais, 2014, p. 238).

\section{DÉBIL CRIMINALIDAD, DÉBIL REPRESIÓN}

La concepción de la mujer delincuente ha tenido una particularidad: destacar cierta minoría de edad caracterizada en una irresponsabilidad de su accionar, así como una supuesta indulgencia en la manera en que se le juzgaba. Esta "debilidad" biológica y de carácter que diversos criminólogos señalaron en su época, especialmente los biologicistas de finales del XIX y principios del XX, se replicó en cierta medida en las representaciones sociales, especialmente cuando se trataba de delitos menores.

En la cobertura periodística resulta evidente una vinculación entre el accionar delictivo y la baja racionalidad. La mujer, según las notas, actuaba bajo el impulso; en cambio la planeación y la frialdad estaban con los criminales masculinos; por lo tanto, al ser acciones de menor importancia resaltaba un tono de condescendencia. Como la ocasión en que una mujer quemó el jacal en el cual vivían sus compañeras, el acto mismo no tuvo mayores consecuencias porque aquellas no se encontraban presentes; no obstante, el órgano destacaba la amonestación de parte del juez y su consigna de etiquetar como "chiste" este accionar. ${ }^{23}$ Algo propio de un individuo considerado inmaduro.

Los impulsos en ocasiones pasaban a mayores, a las agresiones físicas, como en un texto titulado "el monstruo de los celos" donde dos mujeres alcoholizadas tuvieron un altercado debido a una disputa por obtener la devoción de un masculino. ${ }^{24}$ En el mismo tenor, se remite la historia de una mujer que le propinó un ladrillazo a un ex novio,

23 BPEJ, HH Juan Panadero, Guadalajara, domingo 29 de mayo de 1887, tomo XV, núm. 1540, p. 2.

24 BPEJ, HH Juan Panadero, Guadalajara, jueves 30 de junio de 1887, tomo XV, núm. 1548, p. 2. 
cuando éste iba caminando en compañía de su pareja para recibir la bendición nupcial. ${ }^{25}$ Este tipo de acciones estaban vinculadas a una inversión de papeles en el cual los hombres pasaban a ser las víctimas de mujeres insanas, histéricas, fuera de sí. Aquí el matiz estribó en el tratamiento diferenciado, ya que también se publicaron en Juan Panadero diversos textos acerca de agresiones derivadas, según el periódico, de los celos generados por las mujeres. ${ }^{26}$ Así, la mujer se presentaba como razón de la violencia, como en el caso de la aprehensión de José María Martín quién asesinó a Pedro Rivera por una mujer, en este caso, en la nota titulada “iSiempre las mujeres!” el periódico se preguntaba:“¿Hasta cuándo dejarán las mujeres de ser causa de tales cositas? Algún fundamento tiene lo de 'no hay mal que por mujer no venga' ${ }^{27}$ Es importante señalar que este órgano escribía en un tono satírico y burlón, aun así, esta afirmación concuerda con las percepción que se tenían de la mujer cuando ésta rompía el modelo del deber ser.

En el mundo del robo, también encontramos en los expedientes situaciones que vinculaban a la mujer como la generadora de actos delictivos. En ciertos robos domiciliados no violentos sucedía que los inquilinos encontraban in fraganti a los ladrones y los capturaban en las azoteas o intentando horadar las puertas y ventanas. Estos encuentros se reconstruían al momento de realizar las declaraciones de las partes, en las cuales las mujeres se convertían en el centro de argumentos exculpatorios, los cuales residían en establecer las intenciones no delictivas de los hombres; al contrario, ellos estaban ahí porque tenían una cita amorosa con una femenina. Por lo tanto, se asentaba que el hombre entraba no por razones criminales, sino carnales. Por supuesto, estos pactos se daban de forma oculta y poco clara, por lo que no había forma de comprobarlo más que con los dichos de los acusados y las negaciones de sus contrapartes (que en realidad no se tomaban en cuenta).

Así, por ejemplo, a Mónico Mujica (jornalero, 30 años, soltero) se le acusó de robo con violencia de las cosas, en específico de la horadación de la puerta de la casa de Pablo Gómez. Cuando estaba haciendo el hoyo de la entrada fue descubierto y arrestado por el dueño. El acusado afirmó que tenía una aventura amorosa con "una mujercilla de por allî", lo cual fue tomado como cierto por el juez de segunda instancia, el cual estableció que las intenciones delictivas de Mujica eran poco claras y lo absolvió. ${ }^{28}$ Años después, se acusó a Miguel Castillón (jornalero, 18 años, soltero) por delitos de intento de robo contra Celedonia Rubio. Una noche Castillón horadó la puerta de la casa de la víctima, afirmó que no era su intención robar, sino que tenía relaciones ilícitas con Rubio por lo que, estando ebrio, rompió la puerta para entrar a verla. La mujer afirmó que en el pasado tuvo una "amistad ilícita" con el acusado, pero ya no la tenía al momento de los hechos. ${ }^{29}$ Al igual que sucedió en el caso anterior, el acusado fue absuelto. domingo 28 de septiembre de 1884, tomo XIII, núm. 1263, p. 2.

27 BPEJ, HH, Juan Panadero, Guadalajara, jueves 6 de agosto de 1885, tomo XIV, núm. 1352, p. 3.

28 BPEJ, STJ, Criminal, 1849, caja 2, exp. 10148.

29 BPEJ, STJ, Criminal, 1858, caja 4, exp. 17174. 
Cuando existía violencia, aunque fuera menor, los argumentos sobre las nulas intenciones delictivas en pos de una cita pactada permanecían como válidos. Cuando Pioquinto Vargas (jornalero, 20 años, soltero) entró a la casa de Tranquilina Ruvalcaba robó algo de ropa e intentó salir. La mujer lo detuvo, ante lo cual Vargas sacó su cuchillo y la hirió. En su declaración, el acusado dijo que tenía "compromiso" con Tranquilina y que la herida que tenía se la causó Blas Díaz, un hombre que también requería de la amistad de la mencionada. Este último declaró que Vargas era una "mujer mala" y su casa parecía "mesón". ${ }^{30}$ Pese a la herida de la mujer, en un contexto en el cual un robo violento era muy penado, la resolución tanto de la primera como de la segunda instancia fue la absolución del acusado. Lo anterior comprobaba que, en una confrontación de dichos, los emitidos por las femeninas no tenían el mismo peso que su contraparte en lo relativo a establecer culpas. Es posible que al ser consideradas mujeres de "costumbres relajadas" no fueran tomadas en serio en sus declaraciones.

Los hechos violentos llegaban a las últimas consecuencias; por ello, también se remitieron casos de asesinas, como una mujer que quemó con petróleo a su madre porque la creyó bruja y buscaba evitar la condena de la familia. ${ }^{31} \mathrm{O}$ bien la historia de Catarina Hernández etiquetada como "infame mujer" quien asesinó con un puñal a Gregoria Valdivia, su prima hermana. Hernández recién había cumplido una condena por robo en la Penitenciaría de Escobedo. De acuerdo con la nota, el móvil se llevó a cabo por una venganza, pues Hernández sospechaba que Valdivia la había delatado. Para el periódico lo destacado residía en que la mujer no mostró arrepentimiento: "no se intimidó ni un solo instante, no depuso su iracundo seño ni su actitud agresiva", sino que aseguró que lo volvería a hacer. Sin duda se trataba de una mujer fuera de lo común, para el periódico la rareza residía en la falta de sumisión: "esta mujer no es la hembra del hombre, es la hembra de un tigre de Hircania a quien es preciso encerrar con triple llave en la más segura de las jaulas". ${ }^{32}$ Así, en este caso no debería existir consideración alguna. Resulta interesante la vinculación de la mujer con la animalidad, en este caso la referencia hacia la pareja de un tigre que, en los textos clásicos se ha descrito como particularmente fiero. De este modo, no se trataba de una mujer (en el sentido de como se le estereotipaba) porque aquella era decorosa, recatada y frágil, si bien irracional e impulsiva. En este caso, la ferocidad era propia de una bestia.

Ahora bien, a excepción de los acontecimientos más violentos, existía la percepción que en los casos de delitos menores había una tendencia a tener cierta benevolencia hacia las mujeres en relación con la administración de justicia. En palabras de Farge: "la idea de que la mujer es una menor que 'merece' por tanto un tratamiento paternal pesa[ba] en las deliberaciones, incluso en materia de infanticidio o de aborto, en que las tasas de absolución son muy elevadas" (Farge, 1991, p. 92). Speckman, por su parte, afirma que ciertas

30 BPEJ, STJ, Criminal, 1849, caja 4, exp. 10240.

31 BPEJ, HH, Juan Panadero, Guadalajara, jueves 28 de julio de 1887, tomo XV, núm. 1557, p. 2.

32 BPEJ, HH, Juan Panadero, Guadalajara, domingo 21 de julio de 1889, tomo XV, núm. 2046, p. 2. 
criminales, entre ellas algunas ladronas, eran castigadas severamente pues se trataba de individuos que eran doblemente trasgresores, por un lado, de la ley y, por otro lado, de la convención social, pues "se pensaba que las criminales no solo cometían un delito sino que, al hacerlo, faltaban a las obligaciones y atributos femeninos" (Speckman, 1997, p. 196). En este caso hay también un matiz importante, la buena fama pública era un medio fundamental para poder sortear favorablemente una acusación, pues se tomaba en cuenta al momento de las resoluciones. Las convenciones en torno a las buenas costumbres variaban de acuerdo al sexo y la condición social, por lo que en muchos casos tenían un peso determinante en las sentencias.

\section{CONCLUSIONES}

A lo largo del trabajo ha sido posible observar la manera en la cual las convenciones sobre el género permearon, por un lado, en el imaginario colectivo y, por el otro, incidieron en la manera cómo los individuos se desarrollaban socialmente. En primer lugar, destacan las numerosas referencias que había hacia el deber ser femenino, en un contexto en el cual se estaban forjando las bases del Estado moderno mexicano. La mujer tenía un rol en esa construcción, pero limitado al hogar y la familia como centro de la organización social. En ese sentido, la forma en que se representó a la criminal tuvo dos vertientes, de un extremo hubo sorna, burla y condescendencia al establecer las emociones y sentimientos femeninos como sucedáneos de la minoría de edad, de la debilidad y la fragilidad. En el otro, hubo opiniones severas en contra de aquellas mujeres que no se adecuaron al modelo burgués de mujer sumisa. Aquellas trasgresoras que mostraban ferocidad, eran las parejas de los tigres, las infames.

En el ámbito delictivo, la participación de la mujer fue importante en tanto participó en un sinnúmero de robos menores (incluso se podría afirmar que era una de sus especialidades) y también como receptadora y colaboradora en robos más planeados. En ambos casos fue necesario elaborar una revisión de textos con perspectiva de género, ya que en los mismos documentos suele haber silencios, omisiones por parte de los escribanos y jueces que no tomaban a la mujer, sino como un personaje tangencial, pues no solían tomársele los generales y sus declaraciones no tenían el mismo peso inculpatorio. En suma, recuperar esas voces, esas experiencias, así como la relación de estos personajes con los contextos marginales, resulta necesario para comprender que en el mundo delictivo fue mucho más complejo que las generalizaciones suelen mostrar. 


\section{ARCHIVOS CONSULTADOS}

BPEJ Biblioteca Pública del Estado de Jalisco.

$\mathrm{HH}$ Hemeroteca Histórica.

STJ Supremo Tribunal de Justicia.

\section{BIBLIOGRAFÍA}

Altamirano, I. (2010), El Zarco / Navidad en las Montañas. Porrúa, México.

Avedaño, Y. (2018): "Romper el modelo: mujeres, delito y reclusión en la cárcel del divorcio de Santa Fe", Maguaré, 32 (1), 47-74. DOI: https://doi.org/10.15446/mag. v32n1.76163

Benítez, L. (2014), Por la palabra de matrimonio. El rapto en Guadalajara (1885-1933). Universidad de Guadalajara, Guadalajara. DOI: https://doi.org/10.31836/lh.19.7154

Carner, F. (2006): "Estereotipos femeninos en el siglo XIX” en Ramos, C. (Coord.). Presencia y transparencia: la mujer en la historia de México, El Colegio de México, 99-112.

De Souza, M. (2005), De costumbres y leyes. Abigeato y derechos de propiedad en Chihuahua durante el Porfiriato. El Colegio de México / El Colegio de Michoacán, México.

Farge, A. (1991): "La historia de las mujeres. Cultura y poder de las mujeres: ensayo de historiografía”, Historia Social, 9, 79-101.

García-Peña, A. (2016): "De la historia de las mujeres a la historia de género", Contribuciones desde Coatepec, 31, 1-16.

González, L. (2002), Obras 3. El siglo de las luchas. El Colegio Nacional, México.

González, S. y Iracheta P. (2006): "La violencia en la vida de las mujeres campesinas: el distrito de Tenango, 1880-1910" en Ramos, C. (Coord.). Presencia y transparencia: la mujer en la historia de México, El Colegio de México, 113-144.

Hernández, E. (2015): "Un recorrido por las publicaciones de mujeres en el siglo XIX" en Historia de las mujeres en México. Secretaría de Educación Pública / Instituto Nacional de Estudios Históricos de las Revoluciones en México, 157-181.

Herrera, S. (2017), Ladrones infames y su accionar delictivo. El robo en caminos, domicilios y poblaciones en Jalisco, 1846-1861. Tesis doctoral El Colegio de Michoacán. Zamora.

Isais, M. (2014), "Ley, naturalismo y género. Dicotomías sexuales en torno al delito y la justicia en Guadalajara durante la transición de Independencia” en Ochoa, M., Gómez, N., Isais, M. (Coords.). Mujeres insurgentes, mujeres rebeldes. Universidad de Guadalajara, 231-236.

Lau, A. (1998): "La historia de las mujeres: una historia social o una historia de género" en von Wobeser, G. (Coord.). Cien años de investigación histórica en México. Universidad Nacional Autónoma de México / Universidad de Guanajuato, 159-169. 
Marín, M. (2016): "Espacios de reclusión femenina en la ciudad de Puebla (1862-1867)", Revista de Historia de las Prisiones, 2, 150-165.

Núñez, S. (2016): "Los estragos del amor. Crímenes pasionales en la prensa sensacionalista de la ciudad de México durante la posrevolución”, Trashumante, 7, 28-51.

Piccato, P. (2015), La tiranía de la opinión. El honor en la construcción de la esfera pública en México. El Colegio de Michoacán / Instituto Mora, Zamora.

Pulido, G. (2016): El mapa "rojo" del pecado. Miedo y vida nocturna en la ciudad de México 1940-1950. Instituto Nacional de Antropología e Historia, México. DOI: https://doi.org/10.24201/hm.v70i1.3785

Rafart, G. (2008), Tiempo de violencia en la Patagonia. Bandidos, policías y jueces 1890-1940. Prometeo Libros, Buenos Aires.

Ramos, C. (2006): "Señoritas porfirianas: mujer e ideología en el México progresista, 1880-1910" en Ramos, C. (Coord.). Presencia y transparencia: la mujer en la historia de México, El Colegio de México, 145-162.

Riley, D. (1988), Am I That Name? Feminismo and the Category of 'Women' in History. McMillan Press, London.

Saloma, A. (2000): "De la mujer ideal a la mujer real. Las contradicciones del estereotipo femenino en el siglo XIX”, Cuicuilco, 18 (7), pp. 1-18.

Santillán, M. (2017): "Mujeres delincuentes e imaginarios. Criminología, cine y nota roja en México, 1940-1950”, Varia historia, 62 (33). 389-418. DOI: https://doi. org/10.1590/0104-87752017000200006

Sigüenza, F. (2018): “La ex Acordada y Belén, una visión de la rehabilitación penitenciaria en la prisión femenina en México (1833-1882)", Relaciones, 154, 193-223. DOI: https://doi.org/10.24901/rehs.v39i154.292

Speckman, E. (1997): “Las flores del mal. Mujeres criminales en el Porfiriato", Historia Mexicana, 47 (1). 183-229.

Speckman, E. (2018): "Horrorosísimos crímenes y ejemplares castigos: contexto historiográfico, temas, enfoques y aportaciones" en Speckman, E. Horrorosísimos crímenes y ejemplares castigos. Una historia sociocultural del crimen, la justicia y el castigo (México, siglos XIX y XX), El Colegio de San Luis / Universidad Autónoma de Aguascalientes, 29-65.

Taylor, W. (1993): “Amigos de sombrero: patrones de homicidio en el centro rural de Jalisco, 1784-1820" en Escobar, A. (Coord.). Indio, nación y comunidad en el México del siglo XIX, Centro de Estudios Mexicanos y Centroamericanos / Centro de investigaciones y Estudios Superiores en Antropología Social, 63-103.

Vanderwood, P. (1986), Desorden y progreso. Bandidos, policías y desarrollo mexicano. Siglo Veintiuno Editores, México.- 